\title{
EXPERIMENTAL INVESTIGATION ON PERFORMANCE OF SINGLE CYLINDER FOUR STROKE SPARK IGNITION ENGINE WITH MODIFICATION OF PISTON CROWN
}

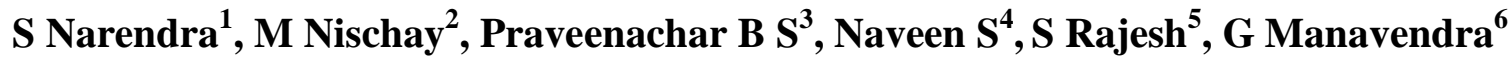 \\ ${ }^{1} M-$ Tech Student, Department of Mechanical Engineering, B.I.E.T Davanagere, Karnataka, India \\ ${ }^{2,3,4}$ B.E Student, Department of Mechanical Engineering, B.I.E.T Davanagere, Karnataka, India \\ ${ }^{5}$ Assistant Professor, Department of Mechanical Engineering, B.I.E.T Davanagere, Karnataka, India \\ ${ }^{6}$ Associate Professor, Department of Mechanical Engineering, B.I.E.T Davanagere, Karnataka, India
}

\begin{abstract}
A decent swirl advances the quick burning and enhances the efficiency for engine which is preferably running at low speeds in order to have low mechanical losses and empowering good combustion efficiency. Subsequently to create high turbulence preceding burning inside the cylinder, swirl prompted by the bay channel inside the cylinder head will be useful. The automobile vehicles still satisfying demands for high performance, requires immense efforts to create new engine ideas and deliver less emission. Swirl is used in SI engine to speed up the combustion process in four stroke engines It increases turbulence and accelerates chemical action by intimating mixing of fuel and oxygen there by weak mixtures can be burnt effectively. In Petrol engine, swirl can increase the rate of fuel-air mixing, reducing the combustion duration for re-entrant chambers at retarded injection timings. Swirl interaction with compression induced squish flow increases turbulence levels in the combustion bowl, promoting mixing. In order to achieve the swirl the piston crown of the conventional petrol engine was suitably modified by forming different shaped grooves on it. This facilitates increased intensity of the swirl for proper mixing of air fuel and to examine their effects on the performance of this engine fuelled with petrol and its blends with ethanol. In the present work Experiment was carried out with unmodified and modified piston with different shapes without much changing compression ratio comparative results shows that better combustion in gasoline engine was obtained with single groove hemispherical piston. Brake thermal efficiency increased by $1.39 \%$ and Brake specific fuel consumption reduced by $3 \%$ for E10P90 blend compared to unmodified piston
\end{abstract}

Keywords: gasoline Engine, Swirl, Hemispherical Piston (HP), Toroidal Piston (TP), Single Grooved Hemispherical Piston (SGH), Brake Power (BP), Brake Specific Fuel Consumption (BSFC) and Brake Thermal Efficiency (BTE)

\section{INTRODUCTION}

In Spark ignition engines combustion takes place by igniting the air-fuel mixture through spark from a spark plug. It is observed that the quality of air fuel mixture that governs the proper combustion depends upon proper mixing of air and fuel from the carburetor in case of SI Engine. The air intake chamber geometry plays a key role in governing the quality of $\mathrm{A} / \mathrm{F}$ mixture.

In the assessment of internal combustion engine the performance, efficiency and emission formation depends upon the formation of air fuel blend inside the engine cylinder. The fluid flow analysis plays a vital part for airfuel blend to acquire the better engine combustion, performance and efficiency. Because of the extreme conditions inside a typical IC engine (high combustion temperatures and pressures, precipitation of residue and other combustion products and so on) Experimental test systems have some time restricted in approaching to the above mentioned issue. After clean perception of all the research in swirl movement assumes an import part to increase in engine performance and in addition diminish the emissions.

The ethanol or ethyl alcohol produced in India is fundamentally from molasses the waste item from sugar industries. After extensive research over the years, it has been realized that future energy needs of transport sector may not be fulfilled by one particular alternate fuel. The ultimate choice of alternatives in a particular region depends on availability and economics, apart from its nonpolluting characteristics. In this connection interest is shown in gasoline-ethanol fuel blends in this work.

The concept of project is to improve the quality of $\mathrm{A} / \mathrm{F}$ mixture by making different types of grooves on piston 
crown and to increase the swirl. Design development \& analysis of swirl chamber for optimal quality of $\mathrm{A} / \mathrm{F}$ mixture

\section{MATERIALS AND METHODOLOGY}

\subsection{Materials}

The blend of ethanol and petrol prepared for experimental investigation in three different proportions such as E5P95, E10P90 and E15P85. The name E5P95 indicates that 5\% ethanol in $95 \%$ petrol by volume the other two represents blends with $10 \%$ \& $15 \%$ of ethanol. The blend is prepared by collecting the ethanol and petrol with required proportions in measuring jar and magnetic stirrer is used to have homogeneous mixture. And properties of blends prepared are found out as per ASTM standards is shown in table 1

Table 1:- Properties of blends

\begin{tabular}{|l|l|l|l|l|}
\hline Properties & E0P100 & E5P95 & E10P90 & E15P85 \\
\hline $\begin{array}{l}\text { Calorific value } \\
(\mathrm{KJ} / \mathrm{kg})\end{array}$ & 45200 & 44250 & 43500 & 42750 \\
\hline Density $\left(\mathrm{kg} / \mathrm{m}^{3}\right)$ & 720 & 738.59 & 741.30 & 744 \\
\hline Viscosity $\left(\mathrm{mm}^{2} / \mathrm{s}\right)$ & 0.4246 & 0.4749 & 0.5250 & 0.6247 \\
\hline
\end{tabular}

\subsection{Methodology}

The main objective of this work is to find experimentally the influence of air fuel swirl in the cylinder on the performance of a single cylinder petrol engine. In order to achieve the swirl the piston crown of the conventional petrol engine was suitably modified by forming three different shaped grooves on it modification on piston crown is done by using CNC Machine. The following three modification are made

1) Hemispherical Grooved Piston

2) Toroidal Grooved Piston

3) Single grooved Hemispherical Piston

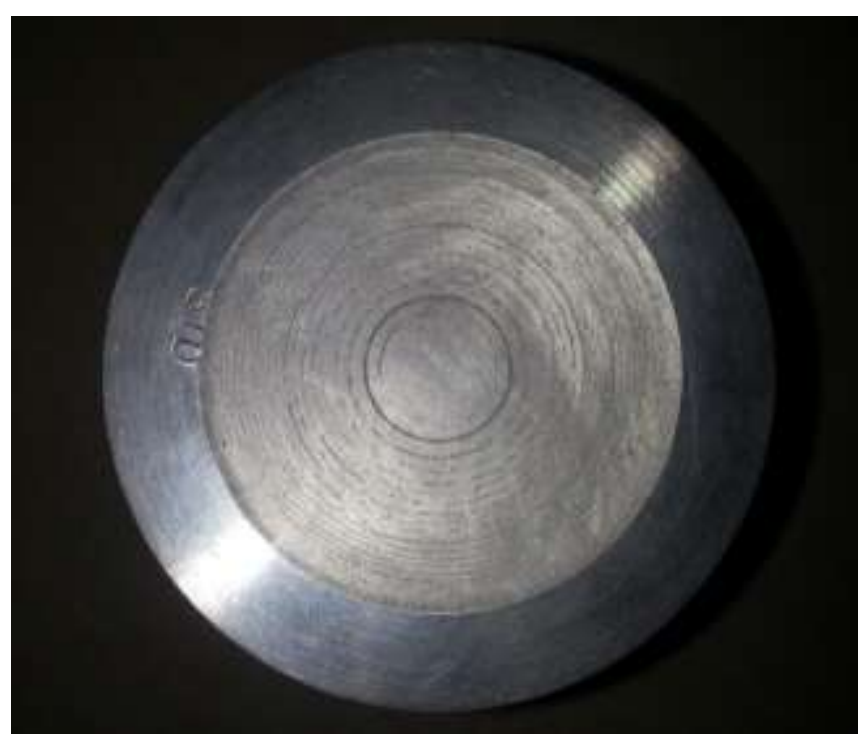

Fig 1:- Hemispherical grooved piston

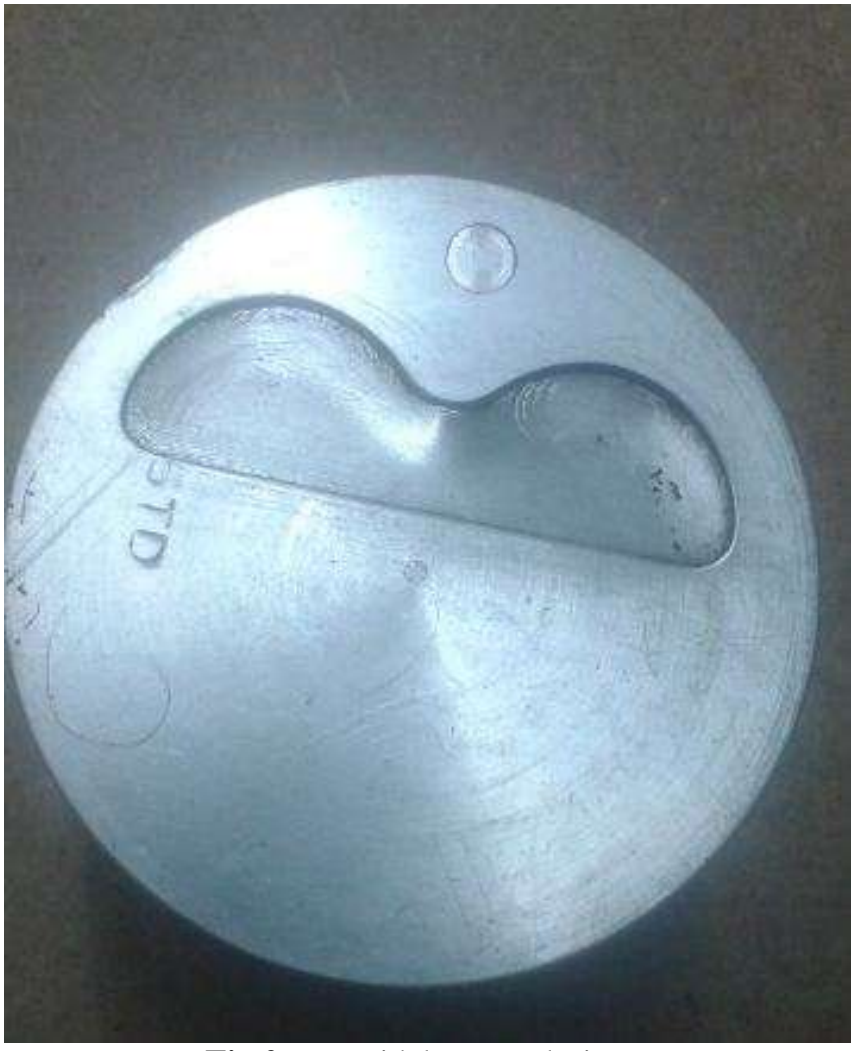

Fig 2:- Toroidal grooved Piston

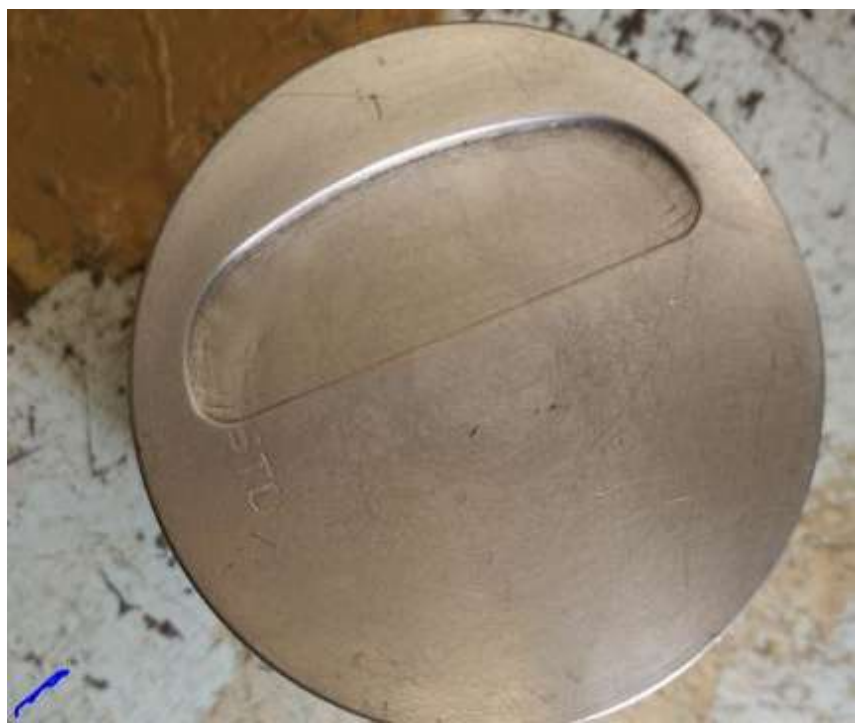

Fig 3:- Single grooved Hemispherical Piston

\subsection{Experimental Setup}

The setup comprises of single cylinder, four stroke gasoline engine having specification as specified in table 2. The spark ignition set up along with rope brake dynamometer, spring balance, and Fuel input measuring system is shown in fig 4.This set-up enables the study of Engine brake power, fuel consumption and thermal efficiency. 


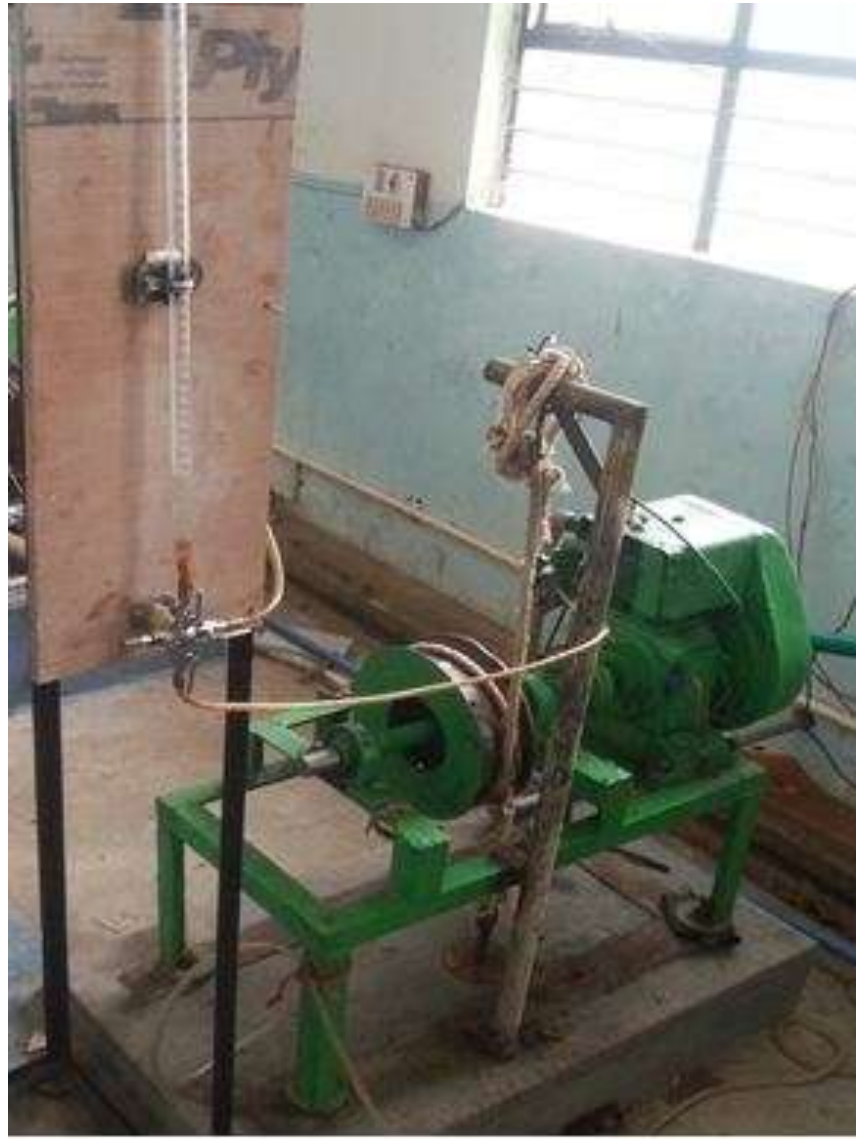

Fig 4:- Pictorial View of 4 Stroke S.I Engine

Table 2:- Engine Specification

\begin{tabular}{|l|l|}
\hline Make & Greaves \\
\hline Type & $\begin{array}{l}4 \text { Stroke, single Cylinder, Air } \\
\text { cooled gasoline engine }\end{array}$ \\
\hline Bore & $70 \mathrm{~mm}$ \\
\hline Stroke & $66.7 \mathrm{~mm}$ \\
\hline Rated Power & $2.2 \mathrm{~kW} \mathrm{@} \mathrm{2650rpm}$ \\
\hline Cooling System & Air cooled \\
\hline Compression Ratio & $\begin{array}{l}\text { Unmodified piston- 4.67 } \\
\text { Hemispherical Grooved piston- } \\
4.709 \text { Toroidal grooved piston-4.704 } \\
\\
\text { Tingle groove hemispherical } \\
\text { piston-4.709 }\end{array}$ \\
\hline
\end{tabular}

\section{RESULTS AND DISCUSSIONS}

\subsection{Pure Gasoline}

\subsubsection{Brake Specific Fuel Consumption}

The BSFC with BP for Various modified pistons is compared with unmodified piston with only petrol and as shown in Fig 5. The BSFC for unmodified piston at full load is $47 \%$ it can be7observed that the engine with HP, TP \& SGH piston gives the BSFC of $49 \%, 45 \%$, and $43 \%$ correspondingly at full loads. It can be observed that there is diminishment of $\mathbf{4 \%}$ fuel consumption with SGH piston compared to unmodified piston. From figure 5 it is concluded that the BSFC was reduced with a rise in BP.
SGH piston was found to offer improved BSFC over the unmodified piston. This may be because of the improved mixing rate in case of SGH piston conveyed by turbulence in the combustion chamber.

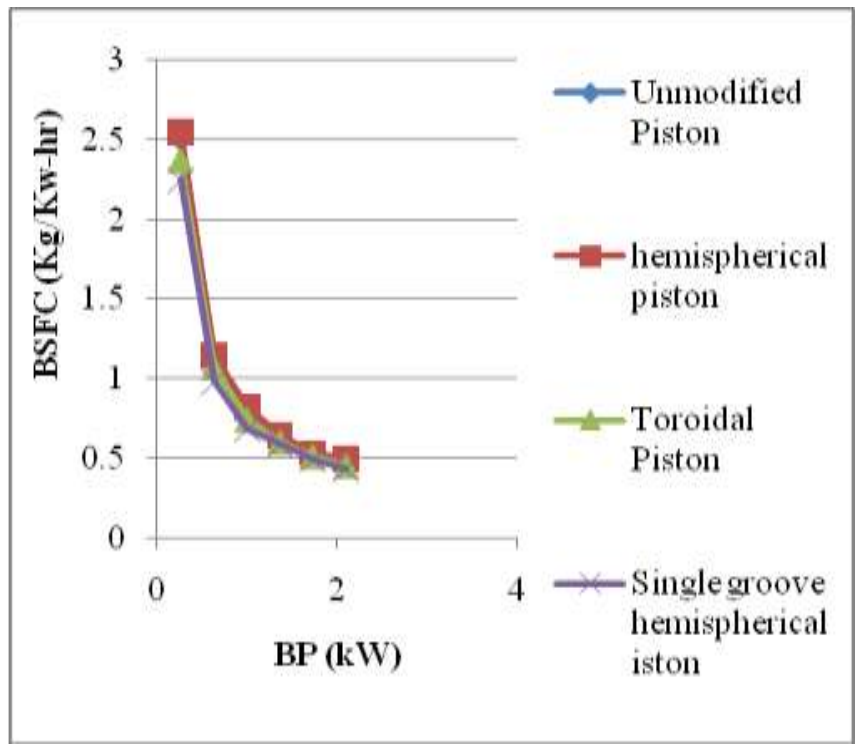

Fig 5 :- BP vs BSFC for E0P100 Blend

\subsubsection{Brake Thermal Efficiency}

The BTE with BP for various modified pistons is compared with unmodified piston with only petrol and as shown in Fig 6. The BTE for unmodified piston at full load is $16.83 \%$ it can be7observed that the engine with HP, TP \& SGH piston gives the BTH of $16.13 \%, 17.46 \%$ \& $18.07 \%$ correspondingly at full loads. It can be observed that there is rise of $1.24 \%$ of BTE with SGH piston compared to unmodified piston. From figure 6 it is concluded that the BTE was increased with a rise in BP. SGH piston was found to offer improved BTE over the unmodified piston. This may be cause of the improved7mixing rate in case of SGH piston conveyed by turbulence in the combustion chamber.

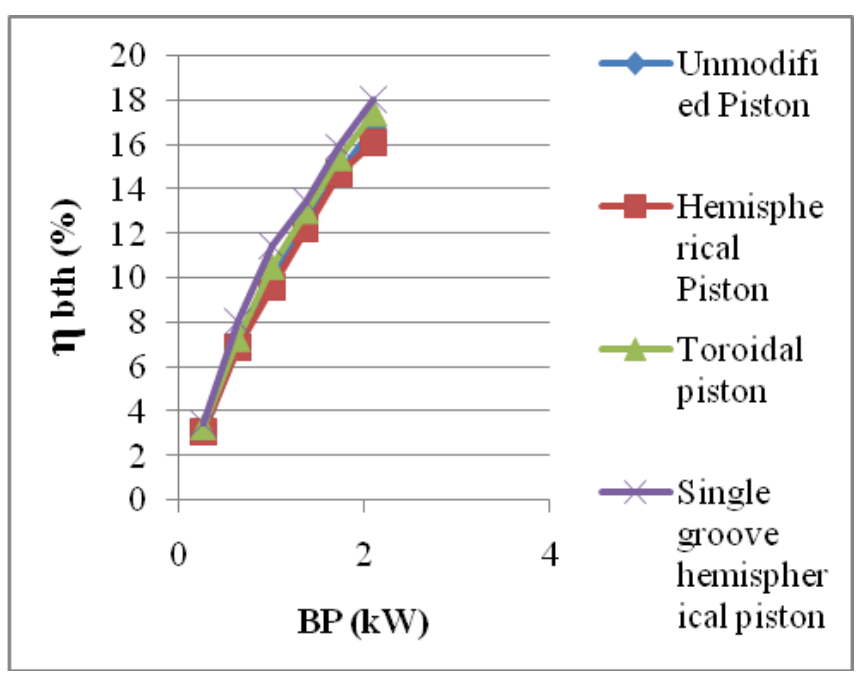

Fig 6 :- BP vs BTE for E0P100 Blend 


\subsection{E5P95 BLEND}

\subsubsection{Brake Specific Fuel Consumption}

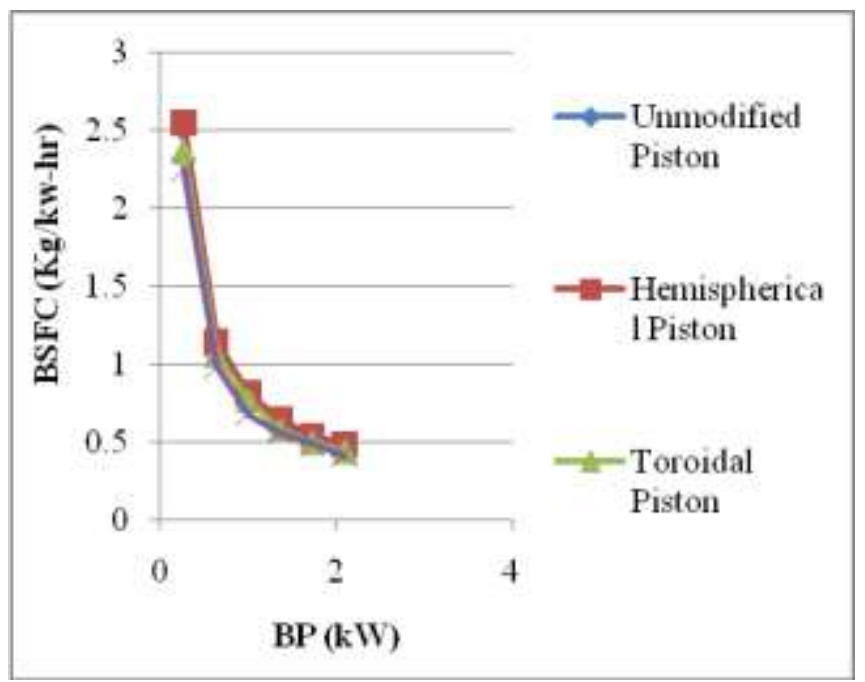

Fig 7 :- BP vs BSFC for E5P95 Blend

The BSFC with BP for various modified pistons is compared with unmodified piston with E5P95 blend as shown in Fig 7. The BSFC for unmodified piston at full load is $46 \%$ it can be7observed that the engine with $\mathrm{HP}$, TP, and $\mathrm{SGH}$ piston gives the BSFC of $48 \%, 44 \%$, and $41 \%$ correspondingly at full loads. It can be observed that there is diminishment of $\mathbf{5 \%}$ fuel consumption with SGH piston compared to unmodified piston. From figure 7 it is concluded that the BSFC was reduced with an increase BP. $\mathrm{SGH}$ piston was found to offer improved BSFC over the unmodified piston. This may be cause of the improved blending rate in case of SGH piston conveyed by turbulence in the combustion chamber. In combustion process by adding ethanol complete combustion is achieved due to more oxygen as well as gives water as product of combustion and compared with gasoline ethanol is having lower heating value.

\subsubsection{Brake Thermal Efficiency}

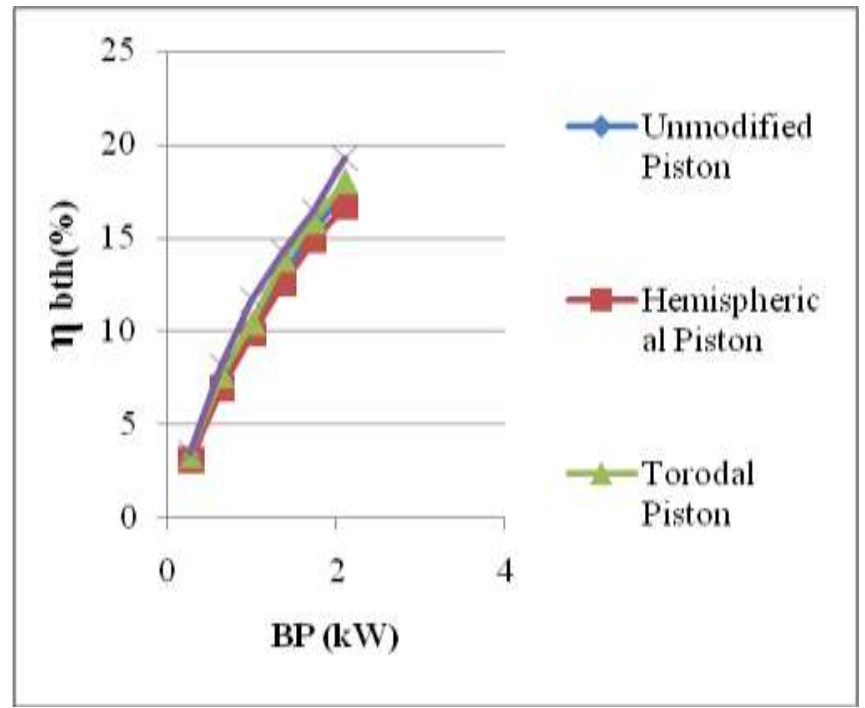

Fig 8 :- BP vs BTE for E5P95 Blend
The BTE with BP for various modified pistons is compared with unmodified piston with E5P95 blend and as shown in Fig 8. The BTH for unmodified piston at full load is $17.38 \%$ it can be observed that the engine with HP, TP, and SGH piston gives the BTE of $16.71 \%, 18.04 \%$, \& $19.29 \%$ correspondingly at full loads. It can be observed that there is rise of $1.91 \%$ of BTE with SGH piston compared to unmodified piston. From figure 8 it is concluded that the BTE was increased with a rise in BP. SGH piston was found to offer improved BTE over the unmodified piston. This may be cause to the improved blending rate in case of SGH piston conveyed by turbulence in the combustion chamber. In combustion process by adding ethanol complete combustion is achieved due to more oxygen as well as gives water as product of combustion and compared with gasoline ethanol is having lower heating value.

\subsection{E10P90 BLEND}

\subsubsection{Brake Specific Fuel Consumption}

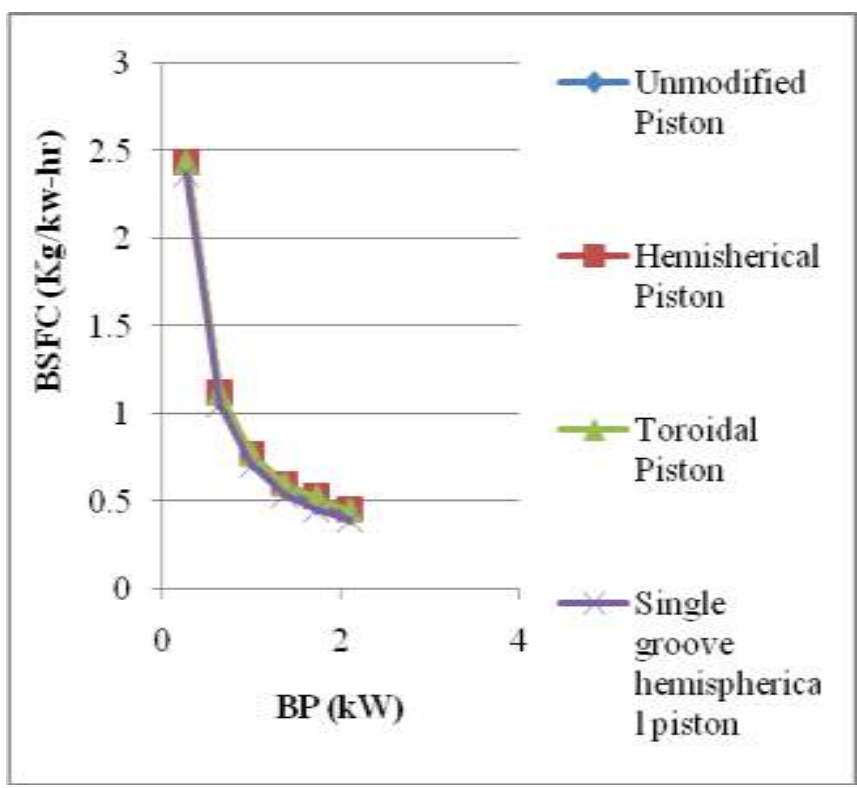

Fig 9 :- BP vs BSFC for E10P90 Blend

The BSFC with BP for various modified pistons is compared with unmodified piston with E10P90 blend as shown in Fig 9. The BSFC for unmodified piston at full load is $43 \%$ it can be7observed that the engine with HP, TP \& SGH piston gives the BSFC of $45 \%, 41 \%$, and $40 \%$ correspondingly at full loads. It can be observed that there is diminishment of $\mathbf{3 \%}$ fuel consumption with SGH piston compared to unmodified piston. From figure 9 it is concluded that the BSFC was7reduced with a rise in brake power. SGH piston was found to offer improved BSFC over the unmodified piston. This may be cause of the improved blending rate in case of SGH piston conveyed by turbulence in the combustion chamber. In combustion process by adding ethanol complete combustion is achieved due to more oxygen as well as gives water as product of combustion and compared with gasoline ethanol is having lower heating value. 


\subsubsection{Brake Thermal Efficiency}

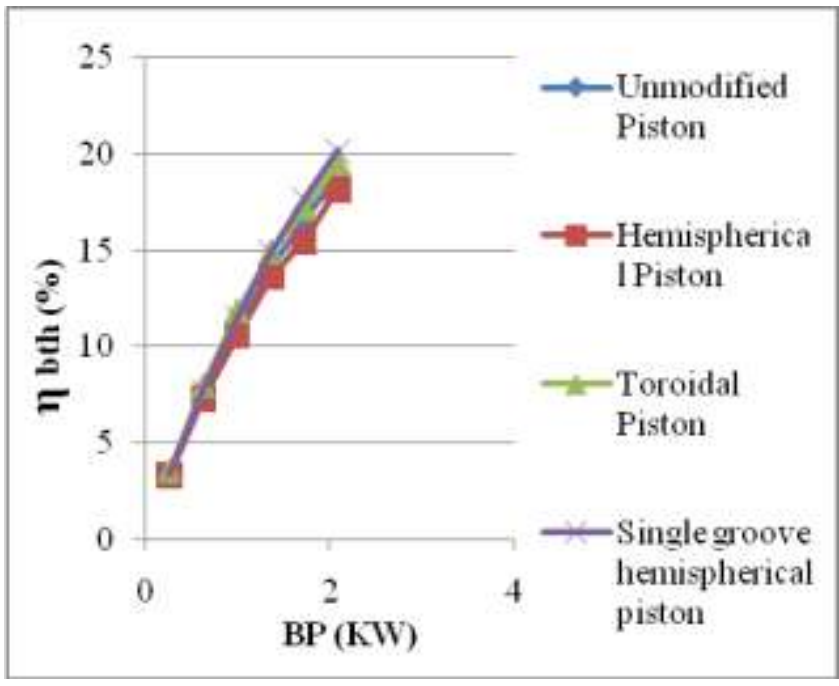

Fig 10 :- BP vs BTE for E10P90 Blend

The BTE with BP for various modified pistons is compared with unmodified piston with E10P90 blend and as shown in Fig 10. The BTE for unmodified piston at full load is $18.8 \%$ it can be observed that the engine with HP, TP \& SGH piston gives the BTE of $18.2 \%, 19.54 \%$, and $20.19 \%$ correspondingly at full loads. It can be observed that there is rise of $1.39 \%$ of BTE with SGH piston compared to unmodified piston. From figure 10 it is concluded that the BTE was increased with an increase brake power. SGH piston was found to offer improved BTE over the unmodified piston. This may be cause of the improved blending rate in case of SGH piston conveyed by turbulence in the7combustion chamber. In combustion process by adding ethanol complete combustion is achieved due to more oxygen as well as gives water as product of combustion and compared with gasoline ethanol is having lower heating value.

\subsection{E15P85 BLEND}

\subsubsection{Brake Specific Fuel Consumption}

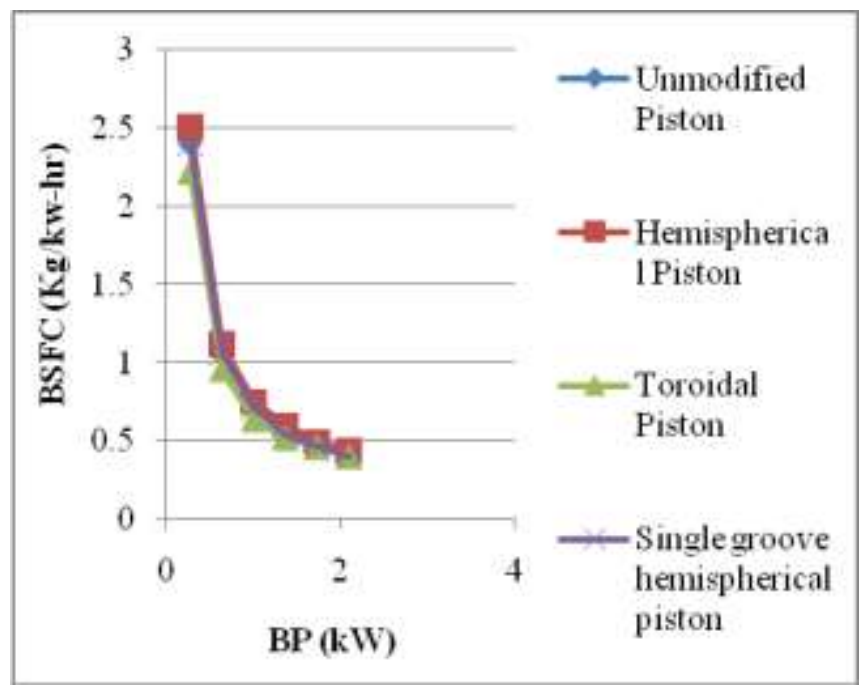

Fig 11 :- BP vs BSFC for E15P85 Blend
The BSFC with BP for various modified pistons is compared with unmodified piston with E15P85 blend as shown in Fig 11. The BSFC for unmodified piston at full load is $42 \%$ it can be7observed that the engine with HP, TP \& SGH piston gives the BSFC of $43 \%, 40 \%$, and $40 \%$ correspondingly at full loads. It can be observed that there is diminishment of $\mathbf{2 \%}$ fuel consumption with $\mathrm{SGH}$ piston compared to unmodified piston. From figure 11 it is concluded that the BSFC was reduced with a rise in BP. $\mathrm{SGH}$ piston was found to offer improved BSFC over the unmodified piston. This may be cause of the improved blending rate in case of SGH piston conveyed by turbulence in the combustion chamber. As we increase the percentage of ethanol in fuel BSFC goes on increases due to unable in correct combustioning of fuel which effects in higher fuel consumption.

\subsubsection{Brake Thermal Efficiency}

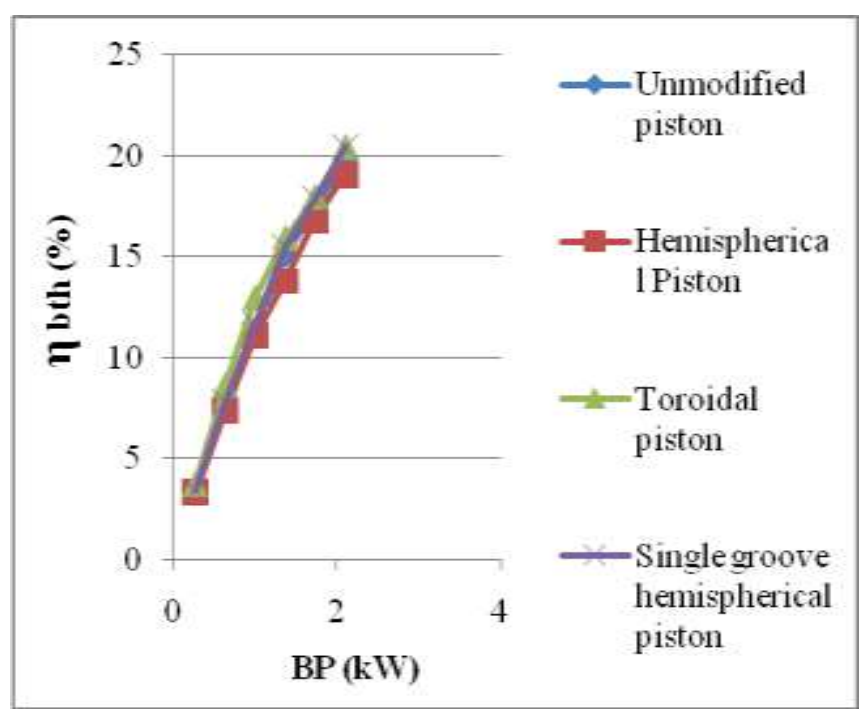

Fig 12 :- BP vs BTE for E15P85 Blend

The BTE with BP for various modified pistons is compared with unmodified piston with E15P85 blend and as shown in Fig 12. The BTE for unmodified piston at full load is $19.80 \%$ it can be7observed that the engine with HP, TP \& SGH piston gives the BTE of $19.1 \%, 20.46 \%$, and $20.46 \%$ correspondingly at full loads. It can be observed that there is rise of $\mathbf{0 . 6 6 \%}$ of BTE with SGH piston compared to unmodified piston. From figure 12 it is concluded that the BTE was increased with a rise in BP. SGH piston was found to offer improved BTE over the unmodified piston. This may cause of the improved blending rate in case of SGH piston conveyed by turbulence in the combustion chamber. As we increase the percentage of ethanol in fuel BTE goes on decreases due to unable in correct combustioning of fuel which effects in lower thermal efficiency.

\section{CONCLUSION}

In the present experiment study engine performance test for 4-stroke S.I engine with petrol and its blend with ethanol was carried out with unmodified and modified pistons. The results were compared with petrol fuel and the main results of this study are summarized as follows 
1). Experiments were conducted by using ethanol and petrol blends mixed with the ratio of 5:95, 10:90 \& 15:85.

2). Brake Thermal Efficiency of single groove hemispherical piston was increased by $1.24 \%$ and BSFC reduced by $4 \%$ for pure gasoline when compared to unmodified piston

3). Brake Thermal Efficiency of single groove hemispherical piston was increased by $1.91 \%$ and BSFC reduced by $5 \%$ for $\mathbf{E 5 P 9 5}$ blend when compared to unmodified piston.

4). Brake Thermal Efficiency of single groove hemispherical piston was increased by $1.39 \%$ and BSFC reduced by $3 \%$ for E10P90 blend when compared to unmodified piston

5). Brake Thermal Efficiency of single groove hemispherical piston was increased by $0.66 \%$ and BSFC reduced by $2 \%$ for $\mathbf{E 1 5 P 8 5}$ blend when compared to unmodified piston.

Performance of E10P90 blend shows an appreciable result compared to E5P95 \& E15P85 blends with single groove hemispherical and unmodified piston because of increase in octane number and higher oxygen content in ethanol makes better combustion of fuel.

Brake thermal efficiency increased by $1.39 \%$ compared to unmodified piston because Single groove hemispherical piston increases turbulence, swirl intensity, homogeneity of air-fuel mixture7and accelerates chemical action by intimating mixing7of fuel and air in combustion chamber. Thus Swirl motion plays a significant7effect on air-fuel mixture, combustion and heat transfer which improves efficiency and7reduces noise.

Hence Ethanol Blends was found to be potential alternative fuel to petrol in case of modified pistons when compared to unmodified piston in SI Engine.

\section{REFERENCES}

[1]. John B. Heywood, -Internal Combustion Engine Fundamentals\|, Tata McGraw Hill edition, 2011.

[2]. V. Ganeshan, -Internal combustion enginell, Tata Mc Graw Hill, 2006.

[3]. Bhanu Pratap patel et al "Effect of spiral grooves in piston bowl on exhaust emissions of direct injection diesel engine" IJRET, Vol: 03, pg. no 131-135.

[4]. V.V. Prathibha Bharathi et al "Influence of in cylinder air swirl on diesel engine performance and emission" IJRET, Vol: 1, pg. no 113-118.

[5]. C.V. Subba Reddy et al "Effect of tangential grooves on piston crown of D.I. diesel engine with blends of cotton seed oil methyl easter" IJRRAS, Vol: 13, pg. no 150-159.

[6]. B.Madhubabu et al "Experimental investigation of a single cylinder 4-Stroke DI diesel engine by swirl induction with two different configuration pistons" IJAIEM, Vol: 3, pg. no 314-319.

[7]. Dr. M.L.S Deva Kumar et al "Effect of cylinder air swirl on petrol engine performance" IJARS, Vol: I, pg.no $1-5$. 